\title{
Methods and techniques for Quaternary paleoenvironmental reconstruction
}

\author{
N'dji dit Jacques Dembele
}

Bamako, Mali, 26-30 September 2016

Since 2009, WAQUA (West African

Quaternary Research Association) has been promoting Quaternary research in West Africa by organizing meetings for researchers involved in Quaternary science.

One of the main issues raised during these meetings is the absence of contributions from West African researchers to the understanding of paleoenvironmental conditions in the region, because of the lack of trained Quaternary scientists. To help address this issue, WAQUA organized a training session for 60 early-career scientists and students from the West Africa region. Attendees were mainly archaeologists, geographers, historians, and botanists, from Cote d'Ivoire, Benin, Mali, Niger and Nigeria.

The four invited speakers discussed Quaternary palynological methods (Chantal Kabonyi, Democratic Republic of Congo), analysis of palynological data (Monique Tossou, Benin), dendrology (Ntamwira Miranda, Democratic Republic of Congo) and quaternary sediments and geomorphological evidences ( $\mathrm{N}^{\prime}$ dji dit Jacques Dembele, Mali).

The workshop focused on seven topics that were addressed during the five days. Day one introduced the stratigraphic framework of the Quaternary and the geomorphological evidences of Quaternary paleoenviron ments. These presentations were followed by debates and discussions.

The second day was devoted to Quaternary sediments: the different types, their textures and structures; the methodology to analyze the textures and structures; the different environments of deposits and the methodology of their reconstruction; the provenance of the sediments using heavy-minerals analysis; and the use of Quaternary sediments to infer Quaternary paleoenvironmental change. While the morning was devoted to theory, participants spent the afternoon on a field trip to see Quaternary sediments of the Niger River at Bamako (Fig. 1)

Day three focused on Quaternary palynology. Methods were presented to collect, treat and extract pollen samples; to make pollen slides and analyze them using the microscope; to count and classify pollen using morphology and typology; and to build pollen diagrams. The afternoon was dedicated to practical courses. The participants learnt to extract and identify pollen, and build a pollen diagram. The used samples were

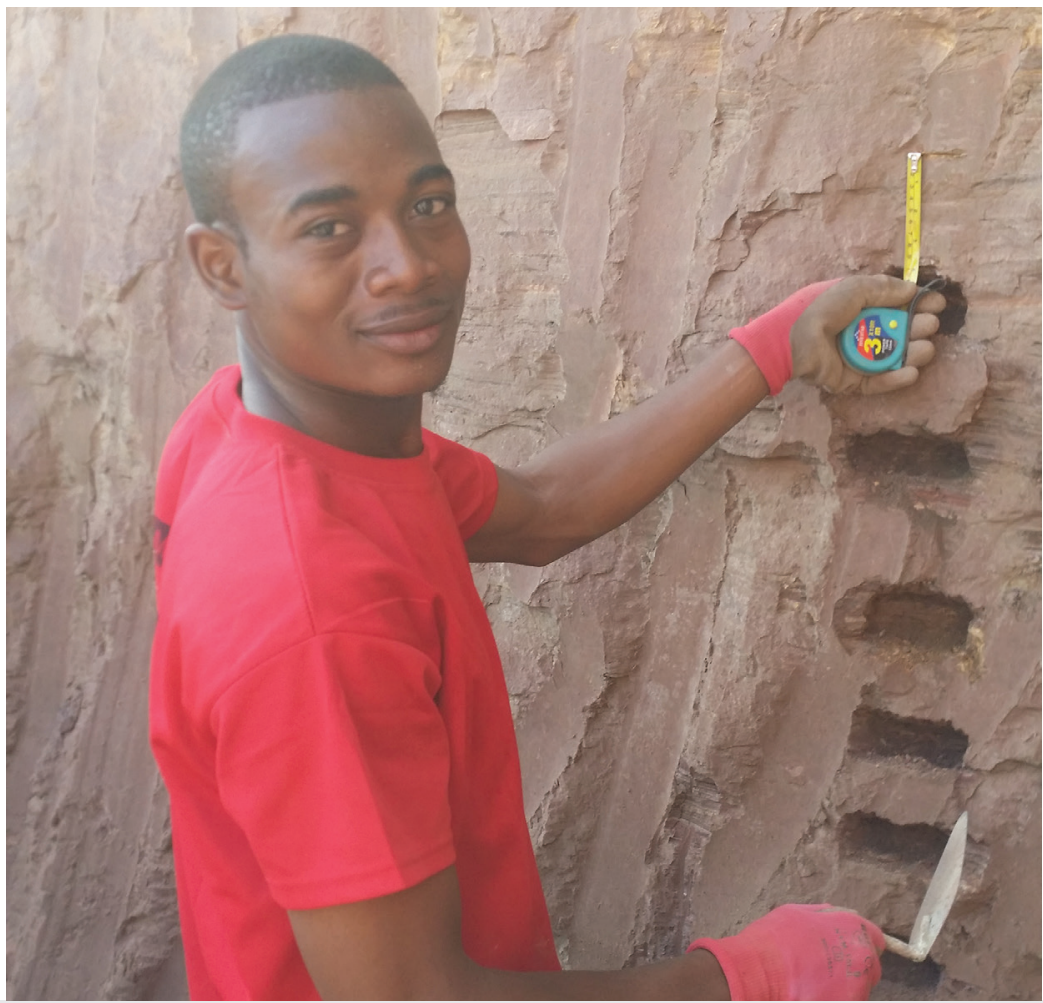

Figure 1: Workshop participant Diarra Cheick Oumar sampling a lacustrine profile of the Niger River right bank, near Bamako, during the field excursion.

from honey, as the preparation of sediment sample necessitates hazardous chemicals such as hydrofluoric acid.

The morning of the fourth day was dedicated to archaeology. Presenters discussed the types of archaeological sites in West Africa, the Paleolithic and Neolithic Periods of West Africa, and the archaeological excavation techniques in the West African context. The afternoon was spent discussing major issues concerning paleoenvironmental research in West Africa, such as the lack of quaternary science courses in West African universities; the fact that African researchers have to send their samples to Europe and Asia for analysis; the lack of communication between researchers from different regions; and the lack of funding.

The fifth and last day of the training workshop was used to define new research paths for possible paleoenvironmental research; to discuss publishing issues (language, high fees, and lack of paleo journals interested in West African case study results). The participants proposed to investigate the options for creating a new PAGES working group on paleoenvironmental dynamics of the Niger River during the Holocene. Also, following on from the day's discussions, a group was mandated to assess the feasibility and scope for a new journal where Quaternary scientists from West Africa could publish their results more easily. It was also proposed that WAQUA should hold a workshop every year so that West African researchers can remain informed about new research methods and techniques.

In addition to the various daily agendas, a session titled "Meet the Experts" was held every day during the training workshop, to enabled early-career researchers and doctorate students to discuss their research issues with senior scientists. The participants felt inspired following this much-welcome training meeting and look forward to implementing their new skills and interact with the new colleagues they met.

\section{ACKNOWLEDGEMENTS}

WAQUA members want to express their sincere gratitude to PAGES and the University of Social Sciences and Management of Bamako (USSGB) for their financial and material support, and for their encouragements.

\section{AFFILIATION}

Faculty of History and Geography, University of Social Sciences and Management of Bamako, Mali

\section{CONTACT}

N'dji dit Jacques Dembele: ndjijacques@icloud.com 